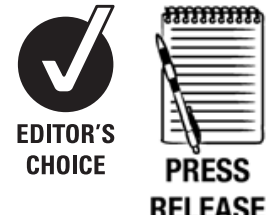

Centre for Social Ethics and Policy, Law School, University of Manchester, Manchester, UK

\section{Correspondence to}

Dr Amel Alghrani, Centre for Social Ethics and Policy, Law School, University of

Manchester, Manchester, M13

9PL, UK; amel.alghrani@

manchester.ac.uk

Accepted 1 July 2010 Published Online First 31 January 2011

\title{
Healthcare scandals in the NHS: crime and punishment
}

\author{
Amel Alghrani, Margaret Brazier, Anne-Maree Farrell, Danielle Griffiths, Neil Allen
}

\section{ABSTRACT}

The Francis Report into failures of care at Mid Staffordshire NHS Foundation Trust Hospital documented a series of 'shocking' systematic failings in healthcare that left patients routinely neglected, humiliated and in pain as the Trust focused on cutting costs and hitting government targets. At present, the criminal law in England plays a limited role in calling healthcare professionals to account for failures in care. Normally, only if a gross error leads to death will a doctor or nurse face the prospect of prosecution. Doctors and nurses caring for patients under the Mental Health Act 1983 and the Mental Capacity Act 2005 may however be prosecuted for wilful neglect of a patient. In the light of the Francis Report, this article considers whether the criminal offence of wilful neglect should be extended to a broader healthcare setting and not confined to mental healthcare.

In the light of the Francis Report, ${ }^{1}$ this article considers whether the criminal offence of wilful neglect should be extended to the healthcare profession.

The criminal law in England, unlike France, plays a limited role in calling healthcare professionals to account for failures in care. Normally, only if a gross error leads to death will a doctor or nurse face the prospect of prosecution. Doctors and nurses caring for patients under the Mental Health Act may, however, be prosecuted for wilful neglect of a patient. We ask whether, in the light of the Francis Report into failures of care at Mid Staffordshire Foundation Trust Hospital, a much more general criminal offence of wilful neglect of a patient should be considered.

The Francis Report recounts a series of 'shocking' systematic failings in healthcare that left patients routinely neglected, humiliated and in pain as the Trust focused on cutting costs and hitting government targets. Several doctors and nurses left patients to lie soaked in their own urine and excrement for considerable periods of time. No care was taken to ensure that patients were fed. Basic standards of hygiene were not met, with relatives resorting to taking sheets home to wash. Some families were forced to remove used bandages and dressings from public areas and to clean toilets themselves for fear of catching infections. There was evidence of a high incidence of falls suffered by patients, some of which led to serious injury. Many took place unobserved by staff. In short, patients at Mid Staffordshire during the period covered by the Enquiry were routinely neglected, in some cases with possibly fatal consequences. In other cases the ill treatment and neglect would not be fatal, but the Report recounts that many patients 'suffered horrific experiences that will haunt them and their loved ones for the rest of their lives'.

How will and should the law respond to evidence of such gross dereliction of duty by healthcare professionals, managers and the Trust? The Trust may face prosecution under the Health and Safety at Work Act $1974,{ }^{2}$ but it is unlikely that individuals will be called to account by the criminal law for their own failings. It may be that disgraceful neglect contributed to the premature death of many patients, but, if healthcare professionals and managers responsible for neglecting their patients were to be charged with manslaughter, it would have to be proved beyond reasonable doubt that that individual's neglect caused the death. Were the hospital Trust to be charged with corporate manslaughter (as many relatives demand), it would equally have to be shown that the Trust's gross breach of duty caused death. ${ }^{3}$ The likelihood is that the patients who died were already very sick, and it may well be impossible to determine if the patient died from neglect or the underlying illness. And proof that neglect caused death is crucial.

English law on 'medical manslaughter' is riddled with contradictions. However grievous the neglect of a patient may be, criminal liability is only engaged if the patient dies. If such causation can be proved, then the doctor or nurse may be convicted of gross negligence manslaughter on the basis of evidence of 'gross' error, but there need not be any evidence of recklessness or disregard for the welfare of the patient. What makes an error gross is ill defined, but doctors who have made a fatal error far less culpable than the account of neglect at Mid Staffordshire have been convicted of manslaughter. ${ }^{4}$

In $R v$ Prentice, ${ }^{5}$ two junior doctors made a terrible, but sadly common, mistake while carrying out a procedure in which they were untrained and inadequately supervised. Their patient died and the doctors stood in the dock charged with gross negligence manslaughter, although they were ultimately acquitted on appeal. A general practitioner miscalculated the dose of diamorphine in the middle of the night. He was convicted of manslaughter. ${ }^{6}$ In both cases (and many more), there was no evidence of deliberate disregard for the welfare of the unfortunate patient, but rather evidence of doctors doing their best. Compare this with the gross neglect at Mid Staffordshire Hospital, where some patients were left screaming in pain for hours. The conditions documented in the Francis Report are believed to have contributed to the fact that between 400 and 1200 more people died at this hospital than would have been expected over those 4 years. But 
unless it can be proved beyond reasonable doubt in any individual case that, but for the neglect, the patient would have survived, any prosecution for manslaughter will fail. Should death matter? ${ }^{7}$ Is the conduct that led so many people to suffer intolerably when they were dependent on others any less morally reprehensible if the patient survived?

So should wilful neglect in any healthcare setting be a criminal offence? Offences of wilful neglect already exist in relation to patients who are mentally ill ${ }^{8}$ or mentally incapacitated, ${ }^{9}$ and an analogous offence addresses the care of children. ${ }^{10}$ These offences reflect the fact that society regards wilful neglect and ill treatment of vulnerable members of society as so morally culpable that it should fall within the domain of the criminal law and uses the criminal law to deter both deliberate and thoughtless neglect. Parallels can be drawn with healthcare. Just as a parent, or a mental healthcare professionals, or person entrusted with responsibilities under the Mental Capacity Act has assumed a fiduciary obligation towards a vulnerable individual, so have healthcare professionals and managers who admit patients into their care. Patients who cannot get themselves to the lavatory and/or eat without help are of necessity vulnerable.

Wilful neglect is a conduct crime rather than a result crime (meaning that it need not be shown that tangible injury was caused). The chance element that arises with gross negligence manslaughter, where liability depends on there being a provable death, is absent. It would mean that there would not be the current discrepancy whereby a doctor who finds himself in a difficult situation makes a badly negligent error may find himself facing a manslaughter charge, yet a professional who persistently neglects a patient with no justification or excuse need not fear the criminal law.

How would 'wilful neglect' be defined? Would doctors or nurses covering a busy under-staffed ward, and so unable to attend to all patients' needs on time, run the risk of incurring the wrath of the criminal law because of the system failings beyond their control? No, this would not be so. In the context of child cruelty, ${ }^{11}$ 'wilful neglect' must mean that the accused must neglect the child, and, at the time, her/his state of mind must be that she/he deliberately neglects the child or acts or omits to act, not caring whether such act or omission amounts to neglect. Section 127 of the Mental Health Act 1983 renders it an offence for any employee or manager of a hospital (independent hospital or care home) to 'illtreat or wilfully neglect a patient' under its care. Ill-treatment of a patient requires a deliberate course of conduct. In $R v$ Newington, ${ }^{12}$ the court held that to prove ill-treatment the prosecution had to show (1) deliberate conduct by the defendant amounting to ill-treatment, irrespective of whether it damaged or threatened to damage the health of the victim and (2) a guilty mind involving either an appreciation by the defendant that she/ he was inexcusably ill-treating the patient or recklessness as to how she/he was treating the patient. Thus, if wilful neglect was extended to the wider healthcare setting, liability would only ensue if the healthcare professional was indifferent to his/her patient's welfare.

Would a criminal offence of wilful neglect result in greater accountability? Accountability is important for patients and their families where harm has been suffered during the course of medical treatment. Patients want an explanation and/or an apology where harm has been caused and wish to ensure that what happened to them does not happen to other patients. Ensuring that those responsible for harm suffered are held to account is crucial to delivering acceptable patient redress. ${ }^{13}$ The Francis Report makes it patently clear that there were no effective internal accountability mechanisms in place to ensure patients received good quality of care. External accountability mechanisms also failed to work. Neither the NHS executive management nor oversight bodies such as the Care Quality Commission or Monitor were able to prevent what happened at Mid Staffordshire Hospital.

In the wake of the scandal, certain healthcare professionals have been referred for disciplinary action, the management board has been replaced, and the CEO has now departed with his contractual entitlement of $£ 400000$. The Francis Report has recommended that regulations be adopted that would result in NHS managers being subject to professional de-accreditation as well as being banned from continuing to work within the NHS where poor quality of care episodes of the type detailed in the Report come to light. The then UK Secretary of State for Health acknowledged that it was a 'longstanding anomaly' that the NHS did not have a robust way of dealing with managers in these sorts of situations, as it would with healthcare professionals such as doctors and nurses. ${ }^{14}$

While we would welcome the adoption of regulations of the type recommended by the Francis Report, do they go far enough? This is not the first time that an episode of abysmal care in an NHS hospital has been exposed, as the enquiry into what happened at the Maidstone and Tunbridge Wells NHS Trust makes clear. ${ }^{15}$ It is unlikely to be the last. More drastic action is needed to ensure that both NHS managers and healthcare professionals are held to account for such episodes, and deter their recurrence. If the criminal law is used on occasion in response to negligent treatment that has resulted in the death of patients, should it also be employed in relation to examples of the kind of dreadful failures of care exposed by the Francis Report?

Across the Channel, the French have been much more willing to make use of the criminal law to hold healthcare professionals to account where harm is suffered by patients. Under the French legal system, there are a range of criminal offences of varying severity and there is no requirement that such harm involve the death of an individual. The option of making use of the criminal law in such circumstances is considered important in societal terms as it sends a message that there are certain categories of blameworthy conduct on the part of an individual, whether in their professional, representative or public capacity, that should be punished in this way for reasons of social utility. In the majority of cases, a criminal conviction in such circumstances results in a fine and/or a suspended sentence rather than a jail term. For professional groups such as doctors, nurses and managers, however, the ultimate stigma lies in the criminal conviction itself, ${ }^{16}$ and they go about their duties in the knowledge that failure to protect the basic interests of their patients will not be sanctioned by society.

While accepting that there are significant differences between the legal systems of England and France, the examination of which is outside the scope of this article, the use of the criminal law for its symbolic and deterrent effects to punish certain categories of blameworthy conduct is worthy of further consideration in the English context. This is particularly so in the case of the sort of conduct by healthcare professionals and managers exposed by the Francis Report. We would therefore urge the UK government to consider creating the criminal offence of wilful neglect, the consequence of which would be that individual NHS managers and healthcare professionals could be held to account for the sort of appalling failures in care revealed in the Francis Report. In the event of conviction, it would send a clear societal message to those with managerial and professional responsibility within the NHS that this sort of 
conduct is not acceptable and indeed undermines the very basis of the social contract on which the NHS was originally founded.

Funding The research for this article has been undertaken as part of an Arts and Humanities Research Council (AHRC) funded project entitled 'The Impact of the Criminal Process on Health Care Ethics and Practice', based at the Universities of Manchester, Lancaster and Birmingham. The support of the AHRC is gratefully acknowledged.

\section{Competing interests None.}

Provenance and peer review Not commissioned; externally peer reviewed.

\section{REFERENCES}

1. Independent inquiry into care provided by Mid Staffordshire NHS Foundation Trust London: The Stationery Office. HC375-I, January 2005-March 2009

2. Quick $\mathbf{0}$. Medical manslaughter: the rise (and replacement) of a contested crime. In: Erin CA, Ost S, eds. The Criminal Justice System and Health Care. Oxford: Oxford University Press, 2007:29-48.
3. Corporate Manslaughter and Corporate Homicide Act 2007, s1(1).

4. Brazier M, Alghrani A. Fatal medical malpractice and criminal liability. Professional Negligence 2009;25:51-67.

5. $R v$ Prentice: $R$ v Sullman [1994] OB 302, CA

6. $\quad R v$ Becker (2000) WL 877688 .

7. Smith JC. The element of chance in criminal liability. Criminal Law Review 1971:63:63-75.

8. Mental Health Act 1983 s 127

9. Mental Capacity Act 2005 s 44

10. Children and Young Persons Act 1933 s 1(1)

11. $\quad R v$ Sheppard [1981] AC $394 \mathrm{HL}$.

12. $\quad R$ v Newington [1990] Criminal Law Review 593.

13. Vincent C, Phillips A, Young M. Why do people sue doctors? A study of patients and relatives taking legal action. Lancet 1994;343:1609-13.

14. Rose D. Stafford Hospital caused 'unimaginable suffering'. The Times 25 Feb 2010.

15. Healthcare Commission. Investigation into outbreaks of Clostridium difficile at Maidstone and Tunbridge Wells NHS Trust, Oct 2007.

16. Spencer JR, Brajeux MA. Criminal liability for negligence-a lesson from across the Channel? International and Comparative Law Quarterly 2010;59:7, 23.

\section{Have confidence in your decision making.}
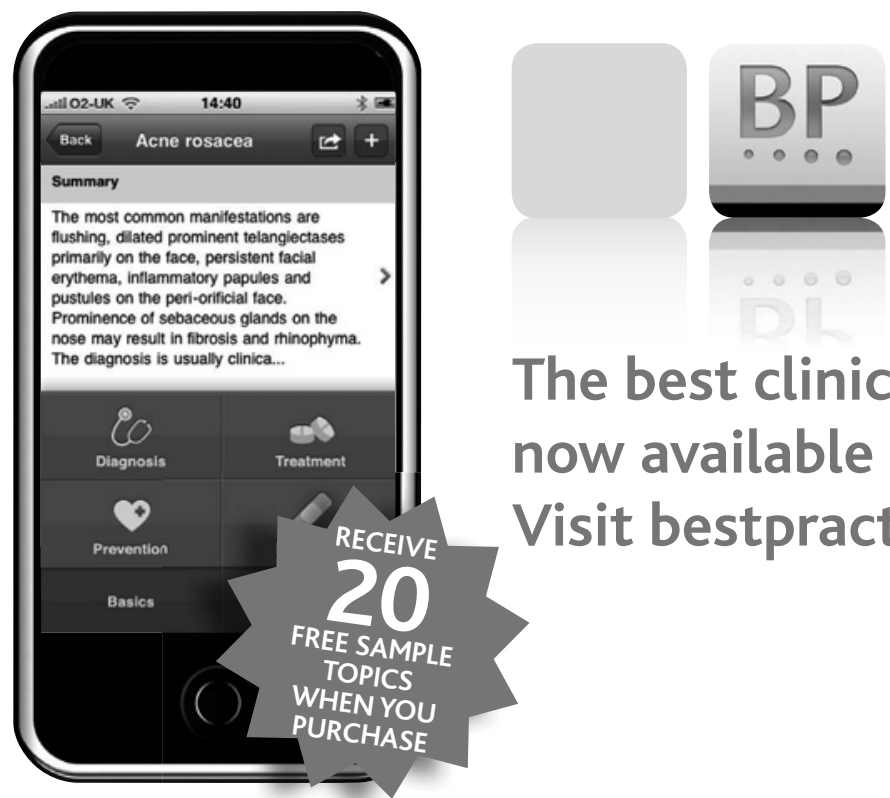

The best clinical decision support tool is now available as an app for your iPhone. Visit bestpractice.bmj.com/app

\section{clinicians $\bullet$ medical students $\bullet$ nurses $\bullet$ healthcare practitioners}

